\title{
CARACTERÍSTICAS DA SILAGEM DE RESÍDUO ÚMIDO DE FÉCULA DE MANDIOCA ADICIONADA DE NÍVEIS DE UREIA
}

\author{
CHARACTERISTICS FROM WET RESIDUE SILAGE OF CASSAVA STARCH \\ WITH DIFFERENT LEVELS OF UREA ADDED
}

\author{
Zambom, M.A. ${ }^{1 \mathrm{~A}}$; Fernandes, T. ${ }^{2 A}$; Soares, M.S.S.P. ${ }^{1 \mathrm{~B}}$; Castagnara, D.D ${ }^{2 *}$; Neres, M.A. ${ }^{1 \mathrm{C}}$; \\ Javorski, C.R. ${ }^{2 B}$ e Cruz, E.A. ${ }^{3}$
}

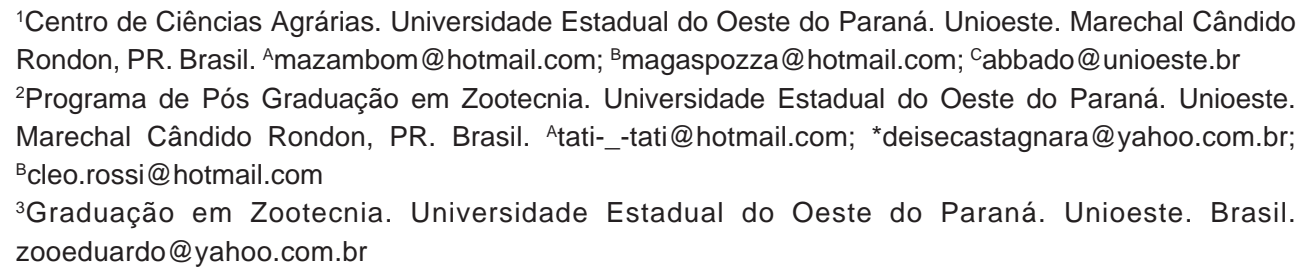

\section{PalaVRas chaVe adicionais}

Composição bromatológica. Desenvolvimento de microorganismos. Subproduto. Nitrogênio não proteico. Ensilagem.

\section{RESUMO}

Este trabalho teve como objetivo avaliar a composição do resíduo úmido de fécula de mandioca (RUFM) ensilado com diferentes níveis de ureia, verificando possíveis alterações na fermentação e em seu valor nutricional, e características microbiológicas e fermentativas. O delineamento experimental adotado foi o inteiramente casualizado em esquema de parcelas subdivididas $4 \times 2$, com os quatro níveis de inclusão de ureia no resíduo úmido de fécula de mandioca $(0 ; 5 ; 10 ; 15$ e $20 \mathrm{~g} / \mathrm{kg}$ na matéria natural) alocados nas parcelas, e as posições de amostragem no silo (superficial e intermediária) alocadas nas subparcelas. O RUFM foi ensilado em silos circulares aéreos de concreto, com capacidade para aproximadamente $1000 \mathrm{~kg}$. A ureia foi adicionada ao RUFM em camadas intercaladas no momento da ensilagem, e o material permaneceu ensilado por um período de 45 dias. Decorrido o período de fermentação, os silos foram abertos e foram realizadas as amostragens para a determinação da temperatura, $\mathrm{pH}$, nitrogênio total, nitrogênio amoniacal, matéria seca, matéria mineral, matéria orgânica, proteína bruta, fibra em detergente neutro (FDN), fibra em detergente

\section{AdDitionAL KEYWORDS}

Chemical composition. Development of microorganisms. By-product. Non-protein nitrogen. Silage.

ácido (FDA), celulose, hemicelulose e lignina, e da população de fungos e leveduras, bactérias ácido-láticas e Clostridium. A adição de ureia até o nível de $20 \mathrm{~g} / \mathrm{kg}$ na matéria natural para a ensilagem do resíduo úmido de fécula de mandioca com aproximadamente $18 \%$ de MS aumenta o $\mathrm{pH}, \mathrm{N}$ total, $\mathrm{N}-\mathrm{NH}_{3}$, proteína bruta, FDN e FDA da silagem. Porém, esta mesma adição, reduz as populações de bactérias ácido láticas, fungos, leveduras e a população total de microorganismos sem alterar o conteúdo de matéria seca, a hemicelulose, celulose e lignina.

\section{SUMMARY}

This study aimed to evaluate the nutritive and microbiological composition and fermentation changes in the residue of wet cassava starch (RWCS) ensiled with different levels of urea. The experimental design was a randomized split plot $4 \times 2$, with four levels of urea added in the residue of wet cassava starch $(0,5,10,15$ and $20 \mathrm{~g} / \mathrm{kg}$ as fed) allocated to plots, and the sampling positions in the silo (superficial and intermediate) allocated to the subplots. The RWCS was ensiled in air 
circular concrete silos with approximately $1000 \mathrm{~kg}$ of capacity. Urea was added to RWCS between layers at the time of ensiling and the material was kept ensiled for a period of 45 days. After the fermentation period, the silos were opened and samples were collected for the determination of temperature, $\mathrm{pH}$, total nitrogen, ammonia, dry matter, mineral matter, organic matter, crude protein, neutral detergent fiber (NDF), acid detergent fiber (ADF), cellulose, hemicellulose and lignin, and the population of fungi and yeasts, lactic acid bacteria and Clostridium. The urea addition to the level of $20 \mathrm{~g} / \mathrm{kg}$ as fed silage for the residue of wet cassava starch with approximately $18 \%$ of DM increases the $\mathrm{pH}$, total $\mathrm{N}, \mathrm{NH}_{3}-\mathrm{N}$, crude protein, NDF and ADF of silage. However, this addition reduce the populations of lactic acid bacteria, fungi, yeasts and the total population of microorganisms without altering the content of dry matter, hemicellulose, cellulose and lignin.

\section{INTRODUÇÃO}

Como os gastos com alimentação animal representam a maior parte dos custos de produção pecuária (Jobim et al., 2007), a utilização de subprodutos da agroindústria na alimentação animal é uma estratégia promissora para a redução dos custos de produção (Souza et al., 2012).

Dentre os resíduos com potencial para a utilização na alimentação de ruminantes destacam-se os subprodutos da industrialização da mandioca (Manihot esculenta Crantz) (Ramalho et al., 2006). O potencial desses subprodutos torna-se ainda mais relevante ao se considerar que o Brasil está entre os maiores produtores de mandioca do mundo, havendo grande produção e disponibilidade desses resíduos neste país.

A massa de fecularia, também conhecida como massa de mandioca, ou resíduo úmido de fécula de mandioca é um dos subprodutos do processamento industrial da mandioca. Sua obtenção se dá por meio da prensagem da mandioca para extração da fécula ou amido na indústria por via úmida (Marques e Caldas Neto, 2002).

Devido ao método de extração da fécula, o resíduo úmido de fécula de mandioca apresenta um alto conteúdo de carboidratos de fácil e rápida fermentação ruminal (Caldas Neto et al., 2000), entretanto, possui também, baixo conteúdo de matéria seca (aproximadamente 15\%) (Abrahão et al., 2006), o que dificulta sua conservação.

Porém, mesmo em condições de alta umidade, resíduos da agroindústria podem ser preservados por meio da ensilagem. Souza et al. (2012) conseguiram preservar de forma satisfatória o resíduo úmido de cervejaria, que também possui baixo conteúdo de matéria seca.

No entanto, o resíduo úmido de fécula de mandioca possui ainda mais um entrave na sua utilização, o baixo valor protéico (Abrahão et al., 2006). Essa característica associada ao baixo conteúdo de matéria seca possibilita a utilização de aditivos alimentares, como a ureia, que além de incrementar o valor nutritivo, pode auxiliar na preservação do material ensilado (Neumann et al., 2010).

Nesse contexto, o trabalho teve como objetivo avaliar o perfil fermentativo e microbiológico e a composição química do resíduo úmido de fécula de mandioca (RUFM) ensilado com diferentes níveis de ureia.

\section{MATERIALEMÉTODOS}

O experimento foi conduzido na fazenda experimental Professor Dr. Antonio Carlos dos Santos Pessoa, Centro de Ciências Agrárias, Unioeste na Região Oeste do Paraná, sob latitude 243 33' 22'" S e longitude $54^{\circ} 03^{\prime} 24^{\prime \prime} \mathrm{W}$, com altitude aproximada de $400 \mathrm{~m}$. O clima é classificado (Sistema Köppen) como Cfa (mesotérmico úmido subtropical de inverno seco). As análises bromatológicas e do perfil fermentativo da silagem foram realizadas no Laboratório de Nutrição Animal, enquanto as análises microbiológicas foram realizadas no Laboratório de Microbiologia (Unioeste).

O delineamento experimental adotado foi o inteiramente casualizado em esquema 
de parcelas subdivididas $4 \times 2$, com os quatro níveis de inclusão de ureia no resíduo úmido de fécula de mandioca $(0 ; 5 ; 10 ; 15$ e $20 \mathrm{~g} / \mathrm{kg}$ na matéria natural) alocados nas parcelas, e as posições de amostragem no silo (subperficial e intermediária) alocadas nas subparcelas, com quatro repetições.

O resíduo úmido de fécula de mandioca (RUFM) utilizado no experimento foi obtido em empresa processadora localizada no município de Marechal Cândido Rondon com as características químicas apresentadas na tabela I e ensilado em silos aéreos circulares pré-moldados de concreto, com capacidade aproximada de $1000 \mathrm{~kg}$ de armazenamento.

Para a inclusão da ureia no RUFM, ambos foram adicionados em camadas proporcionais ao volume individual, visando uma mistura uniforme dos materiais, de forma que a espessura das camadas de RUFM adicionadas ao silo não ultrapassem $5 \mathrm{~cm}$. Após a ensilagem os silos foram vedados com lona plástica preta, sobre a qual foi depositada uma camada de $10 \mathrm{~cm}$ de areia seca, para que ocorresse a formação de um ambiente anaeróbio que assegurasse a fermentação. O resíduo permaneceu ensilado por um período total de 45 dias, após o qual os silos foram abertos para a realização das amostragens. Por ocasião da abertura dos silos, uma camada superficial de $10 \mathrm{~cm}$ do resíduo ensilado foi descartada para redução dos riscos de contaminação das amostras. Após o descarte da camada superficial, as amostragens foram realizadas manualmente na porção superficial e intermediária dos silos.

Para a obtenção das amostras da porção superficial, foram coletadas amostras individuais em quatro pontos distintos na camada de $0-50 \mathrm{~cm}$ no material restante no silo, para formação de uma amostra composta para cada repetição do experimento. Para a caracterização da silagem de RUFM na porção intermediária do silo, as amostras foram coletadas manualmente nos silos, em quatro pontos distintos, em profundidade superior a $50 \mathrm{~cm}$, para posterior obtenção de uma amostra composta.

A decisão de amostragem em dois pontos no interior do silo foi tomada em função de observações relacionadas às diferenças na coloração das silagens localizadas superficialmente e na porção intermediária dos silos. As diferenças de coloração poderiam estar indicando variações no perfil de fermentação dessa silagem, que iriam se refletir em suas características fermentativas, bromatológicas e microbiológicas, e a amostragem e estudo dessas porções separadamente poderia confirmar a existência ou não dessas diferenças.

Após as amostragens, o RUFM foi acondicionado em sacos plásticos identificados

Tabela I. Caracteristicas do resíduo úmido de fécula de mandioca utilizado no experimento. (Characteristics of wet residue of manioc starch used in experimente).

\begin{tabular}{lclc}
\hline MS (g/kg) & 180,3 & Hemicelulose $(\mathrm{g} / \mathrm{kg} \mathrm{MS})$ & 92,8 \\
MM (g/kg MS) & 23,8 & Lignina $(\mathrm{g} / \mathrm{kg} \mathrm{MS})$ & 63,4 \\
MO (g/kg MS) & 975,3 & Celulose $(\mathrm{g} / \mathrm{kg} \mathrm{MS})$ & 256,1 \\
$\mathrm{~PB}(\mathrm{~g} / \mathrm{kg} \mathrm{MS})$ & 28,9 & $\mathrm{pH}$ & 3,6 \\
$\mathrm{~N}$ total $(\mathrm{g} / \mathrm{kg} \mathrm{MS})$ & 4,6 & Clostridium $\left(\log _{10}\right.$ UFC/g) & 6,4 \\
FDN $(\mathrm{g} / \mathrm{kg} \mathrm{MS})$ & 412,3 & Fungos e leveduras $\left(\log _{10}\right.$ UFC/g) & 3,2 \\
FDA (g/kg MS) & 319,5 & Bactérias ácido láticas $\left(\log _{10}\right.$ UFC/g) & 8,8 \\
\hline
\end{tabular}

$M S=$ matéria seca; $F D A=$ fibra em detergente ácido; $F D N=$ fibra em detergente neutro; $P B=$ proteína bruta; $\mathrm{MO}=$ matéria orgânica; $\mathrm{MM}=$ matéria mineral. $\mathrm{UFC}=$ unidade formadora de colônia. 
e no laboratório, cada amostra obtida foi separada em três sub-amostras. A primeira foi acondicionada em bandeja de alumínio e conduzida à estufa de secagem com circulação forçada de ar por 72 horas sob temperatura de $55^{\circ} \mathrm{C}$. Nessa etapa foram tomados os pesos fresco e seco do RUFM para determinação dos teores de matéria seca. Após a secagem, as amostras foram moídas em moinho tipo Willey em peneira de $1 \mathrm{~mm}$ e acondicionadas em frascos plásticos identificados para a realização das análises bromatológicas. Para o estudo da composição bromatológica das silagens, as amostras secas e moídas foram submetidas à procedimentos laboratoriais para a avaliação dos teores de matéria seca (MS), matéria mineral (MM), matéria orgânica (MO), proteína bruta (PB) e nitrogênio total (N-total) segundo a AOAC (1990), fibra em detergente neutro (FDN) e fibra em detergente ácido (FDA) conforme Van Soest et al. (1991), hemicelulose, lignina e celulose (Silva e Queiroz, 2006).

A segunda amostra foi destinada à caracterização fermentativa da silagem, e a terceira amostra para a realização das análises microbiológicas. Para a caracterização do perfil fermentativo das silagens determinou-se a temperatura, o $\mathrm{pH}$ e o teor de nitrogênio amoniacal. A temperatura foi determinada através de termômetro digital do tipo espeto acondicionado em cada camada no interior do silo no momento da abertura. Na determinação do $\mathrm{pH}$, foi realizada extração do exsudado da silagem, por meio de prensa hidráulica, para imediata determinação de $\mathrm{pH}$ (medição em potenciômetro). O nitrogênio amoniacal $\left(\mathrm{N}-\mathrm{NH}_{3}\right)$, foi determinado em sub-amostras in natura de $100 \mathrm{~g}$, segundo metodologia de Bolsen et al. (1992). O perfil microbiológico foi determinado por meio de técnicas de culturas seletivas em solução preparada com $50 \mathrm{~g}$ de amostras das silagens e $450 \mathrm{~mL}$ de água destilada esterilizada.

As populações de microorganismos nas silagens foram determinadas segundo Silva et al. (1997), utilizando os seguintes meios: Potato Destrose Ágar para contagem de fungos filamentosos e leveduras, mantendose as placas em temperatura ambiente por 5 a 7 dias; Lactobacillus MRS Broth para contagem de bactérias ácido láticas, mantendo-se as placas em incubação a $35^{\circ} \mathrm{C}$ por 72 horas e Reinforced Clostridial Ágar para contagem de clostrídios, mantendo-se as placas em incubação anaeróbia utilizando-se jarras com sistema de gás - Park a 35 ${ }^{\circ} \mathrm{C}$ por 72 horas.

Após o período de incubação as colônias foram contadas, utilizando-se um contador de colônias Quebec, sendo passíveis de serem contadas as placas que apresentarem entre 30 e 300 UFC (Unidade Formadora Colônia) por placa de petri e os resultados foram obtidos por meio de média das placas, na diluição selecionada, e expressos em log.

Os resultados obtidos foram tabulados e submetidos à análise de variância sendo testados pelo teste F de Fischer (PimentelGomese Garcia, 2002; Pimentel-Gomes, 2009). Quando constatada a significância dos níveis de adição de ureia, as médias foram estudadas por análise de regressão, testando-se os modelos linear e quadrático considerando-se a ausência de significância para os desvios de regressão. Para a escolha do modelo foi considerado o maior coeficiente de determinação $\left(\mathrm{R}^{2}\right)$. As significâncias dos coeficientes das equações dos modelos de regressão selecionados para cada variável estudada foram testadas pelo teste $t$ de Student (Pimentel-Gomes e Garcia, 2002; Pimentel-Gomes, 2009).

\section{RESULTADOSEDISCUSSÃO}

A temperatura da silagem foi alterada somente pelos níveis de ureia $(\mathrm{p}<0,05)$, sem efeitos para as posições de amostragem da silagem e para a interação dos fatores ( $>0,05)$. A temperatura da silagem decresceu linearmente com a adição dos níveis de ureia, de forma que a cada $1 \mathrm{~g} / \mathrm{kg}$ de ureia adicionados à silagem, houve uma redução 
de $0,56{ }^{\circ} \mathrm{C}$ na silagem (tabela II). Essa diferença pode estar mais relacionada ao acaso do que aos próprios tratamentos estudados na silagem, uma vez que, do ponto de vista biológico, essa redução na temperatura é praticamente insignificante, pois correspondeu a $1,1^{\circ} \mathrm{C}$ da ausência de adição de ureia, para o maior nível de adição (20 g/kg na matéria natural).

Os níveis de ureia também afetaram o $\mathrm{pH}$ da silagem $(\mathrm{p}<0,05)$, que aumentou linearmente com o aumento dos níveis de ureia. Para cada $1 \mathrm{~g} / \mathrm{kg}$ de ureia adicionado ao resíduo úmido de fécula de mandioca, houve um aumento de 0,1324 unidades de $\mathrm{pH}$, fazendo com que o $\mathrm{pH}$ se elevasse de 3,6 na silagem de resíduo úmido de fécula de mandioca sem ureia, para 6,3 na silagem adicionada de $20 \mathrm{~g} / \mathrm{kg}$ de ureia (tabela II). Os resultados sugerem que a adição de mais de $10 \mathrm{~g}$ de ureia para cada $\mathrm{kg}$ de resíduo úmido de fécula de mandioca prejudica a fermentação da silagem, refletindo-se em dificuldades na redução do $\mathrm{pH}$. Segundo Mcdonald et al. (1991), silagens bem preservadas apresentam $\mathrm{pH}$ que variam entre 3,7 e 4,2 e silagens mal preservadas possuem alto $\mathrm{pH}$, entre 5,0 e 7,0, as quais têm concentrações consideráveis de ácido acé- tico e butírico. $\mathrm{O}$ aumento do $\mathrm{pH}$ está relacionado com a adição de ureia $\left(\mathrm{CH}_{4} \mathrm{~N}_{2} \mathrm{O}\right)$, pois com sua hidrólise $\left(\mathrm{CH}_{4} \mathrm{~N}_{2} \mathrm{O}+\mathrm{H}_{2}^{2} \mathrm{O}\right)$, ocorre a formação de $\mathrm{CO}_{2} \mathrm{e} \mathrm{NH}_{3}$. $\mathrm{O} \mathrm{NH}_{3}^{2}$ por sua vez, pode reagir com a água formando o hidróxido de amônia $\left(\mathrm{NH}_{4} \mathrm{OH}\right.$ ) (Kung Jr et al., 2003). A formação desse composto básico contribui para o aumento do $\mathrm{pH}$, inibindo o desenvolvimento de microrganismos indesejáveis, principalmente leveduras, porem, como já dito, ocorre má preservação da silagem.

A matéria seca manteve-se constante em todos os tratamentos, não sendo afetada significativamente por nenhum dos fatores estudados $(\mathrm{p}<0,05)$, e apresentando um valor médio de $190,32 \mathrm{~g} / \mathrm{kg}$. Na confecção de silagens, para a obtenção de alta qualidade, algumas recomendações básicas devem ser seguidas (Ribeiro et al., 2007). Dentre estas, têm-se o teor adequado de matéria seca, que é de $350,00 \mathrm{~g} / \mathrm{kg}$, a fim de favorecer o processo fermentativo, e varia com as características do material que está sendo ensilado (Carvalho et al., 1992). De acordo com Gonçalves et al. (2014) a ensilagem do RUFM com diferentes teores de matéria seca $(128,33$ ou $151,02 \mathrm{~g} / \mathrm{kg})$ não interfere no processo de fermentação.

Tabela II. Perfil fermentativo da silagem de resíduo úmido de fécula de mandioca com adição de níveis de ureia. (Fermentation profile of wet residue of cassava starch silage with addition of urea levels).

\begin{tabular}{lcccccccccccc}
\hline & \multicolumn{4}{c}{ Níveis de ureia $^{1}$} & \multicolumn{2}{c}{ EPM1 } & EPM2 & \multicolumn{5}{c}{$\mathrm{p}^{2}$} \\
Variáveis & 0 & 5 & 10 & 15 & 20 & & & Nível (N) & Posição (P) & $\mathrm{N}^{*} \mathrm{P}$ & $\mathrm{L}^{3}$ & $\mathrm{FA}^{4}$ \\
\hline $\mathrm{T}^{5}$ & 18,4 & 18,4 & 18,2 & 17,8 & 17,3 & 0,24 & 0,21 & 0,027 & 0,957 & 0,974 & 0,003 & 0,629 \\
$\mathrm{pH}^{6}$ & 3,6 & 3,8 & 4,3 & 5,0 & 6,3 & 0,30 & 0,22 & 0,000 & 0,051 & 0,434 & 0,000 & 0,267 \\
$\mathrm{MS}^{7}$ & 186,2 & 191,5 & 190,8 & 191,9 & 191,2 & 0,26 & 0,17 & 0,560 & 0,548 & 0,431 & 0,232 & 0,679 \\
$\mathrm{~N}^{-N_{3}}{ }^{8}$ & 55,1 & 58,9 & 65,9 & 68,1 & 72,3 & 2,14 & 1,29 & 0,000 & 0,016 & 0,680 & 0,000 & 0,061 \\
$\mathrm{~N} \mathrm{total}^{9}$ & 4,7 & 9,2 & 12,2 & 19,6 & 22,3 & 0,02 & 0,01 & 0,000 & 0,718 & 0,874 & 0,000 & 0,051 \\
\hline
\end{tabular}

$\mathrm{T}=$ temperatura ${ }^{\circ} \mathrm{C} ; \mathrm{MS}=$ matéria seca $(\mathrm{g} / \mathrm{kg}) ; \mathrm{N}-\mathrm{NH}_{3}\left(\%\right.$ do $\mathrm{N}$ total); $\mathrm{N}$ total $(\mathrm{g} / \mathrm{kg}$ de $\mathrm{MS}) ;{ }^{1} \mathrm{~g} / \mathrm{kg}$ na matéria natural; ${ }^{2}$ significância testada ao nível de $5 \%$. ${ }^{3}$ regressão linear. ${ }^{4}$ falta de ajuste. ${ }^{5} Y=18,588-0,560 X$ $\left(R^{2}=0,878\right) ;{ }^{6} Y=3,284+0,1324 X\left(R^{2}=0,917\right) ;{ }^{7} Y=188,242 ;{ }^{8} Y=55,34+8,72 X\left(R^{2}=0,977\right) ;{ }^{9} Y=4,464+$ 9,130X $\left(R^{2}=0,979\right)$; EPM1 = erro padrão das médias da parcela; $E P M 2=$ erro padrão das médias da subparcela. 
Os valores de matéria seca obtidos neste estudo são inferiores a alguns teores recomendados na literatura, pois Paiva (1976) recomenda teores de $300-350 \mathrm{~g} / \mathrm{kg}$ de matéria seca no material a ser ensilado, enquanto Mcdonald et al. (1991) citam que os valores de matéria seca devem ser maiores que 250 $\mathrm{g} / \mathrm{kg}$ para evitar maiores perdas por efluentes. No entanto, como as silagens estudadas apresentaram teor médio de matéria seca de 190,32 g/kg e Meskee et al. (1993) obtiveram boas silagens com teores de matéria seca variando de 200 a 290 g/kg, poderia se inferir que, a partir do teor de matéria seca é possível obter silagens de qualidade ensilando-se o resíduo úmido de fécula de mandioca com teores de matéria seca acima de $200 \mathrm{~g} / \mathrm{kg}$. Deve-se ressaltar porém, que Rotze Muck (1994) indicam um teor de matéria seca em torno de $300 \mathrm{~g} / \mathrm{kg}$ no momento da ensilagem para minimizar o potencial para fermentação indesejável, durante o armazenamento da silagem.

Nos valores de $\mathrm{N}-\mathrm{NH}_{3}$, houve significância dos níveis de ureia e das posições de amostragem $(p<0,05)$. O teor de ureia foi superior na camada intermediária, representando 68,3\% do $\mathrm{N}$ total, enquanto na camada superficial foi inferior, o N-NH sentou $60,9 \%$ do $\mathrm{N}$ total. Essa diferença evidencia que pode ter havido uma lixiviação do $\mathrm{N}_{-} \mathrm{NH}_{3}$ formado na superfície ao longo do perfil do resíduo úmido de fécula de mandioca, possibilitando a redução no $\mathrm{N}-\mathrm{NH}_{3}$ da superfície com consequente aumento da sua concentração em profundidade.

Os níveis de ureia ocasionaram um efeito linear crescente no $\mathrm{NH}_{3}$ das silagens em resposta ao aumento dos níveis adicionados (tabela II). Essa elevação era esperado devido a adição de ureia às silagens e ao baixo teor de matéria seca do material ensilado, visto que o $\mathrm{N}-\mathrm{NH}_{3}$ é formado a partir da hidrólise da ureia $\left(\mathrm{CH}_{4} \mathrm{~N}_{2} \mathrm{O}\right)$. A formação do $\mathrm{N}-\mathrm{NH}_{3}$ parece a princípio indesejável, mas em silagens com baixo conteúdo de matéria seca, a formação desse composto contribui na conservação da silagem por controlar a população de leveduras (Siqueira et al., 2007).

No entanto, em relação ao $\mathrm{N}$ total, as proporções de $\mathrm{N}-\mathrm{NH}_{3}$ são consideradas altas, e as silagens obtidas no experimento não podem ser consideradas de boa qualidade, pois de acordo com Benachio (1965), silagens próprias para o consumo devem apresentar tal relação $\mathrm{N}-\mathrm{NH}_{3} / \mathrm{N}$ total inferior a $10 \%$. A recomendação de que o teor de amônia não deve ultrapassar valores de 11 a $12 \%$ do nitrogênio total em silagens bem conservadas, indicam menor intensidade de proteólise durante o processo de fermentação dessas silagens, uma vez que a proteólise no interior do silo é ocasionada pela atuação de bactérias do gênero Clostridium (Mcdonald et al., 1991).

No presente estudo, as proporções de $\mathrm{N}-\mathrm{NH}_{3}$ foram altas devido ao baixo teor de proteína bruta do resíduo úmido de fécula de mandioca que foi ensilado (tabela I), o que contribuiu para evidenciar os efeitos da ureia adicionada. Entretanto, mesmo nos tratamentos em que não houve adição de ureia, foi observada uma alta proporção de $\mathrm{N}-\mathrm{NH}_{3}$ em relação ao $\mathrm{N}$ total $(59,0 \%)$. Esses resultados evidenciam que durante a ensilagem ocorreu atividade dos clostrídios, uma vez que o $\mathrm{N}_{-} \mathrm{NH}_{3}$ é produzido em pequenas quantidades pelas bactérias acido láticas e pela atividade da enzima deaminase das plantas (Jobim e Gonçalves, 2003). Dessa forma, apesar de ter elevado o teor de PB da silagem, a adição de ureia ao resíduo úmido de fécula de mandioca proporcionou a obtenção de uma silagem de baixa qualidade protéica, pois os resultados evidenciam que houve intensa deaminação dos aminoácidos da proteína verdadeira (Jobim et al., 2007), que já se encontrava em baixa concentração no material inicial.

No entanto, segundo Gomide et al. (1974), o elevado teor de $\mathrm{N}-\mathrm{NH}_{3}$ em silagens tratadas com ureia, por si só, nã̃o é um bom indicativo da ocorrência de fermentação indesejável no material ensilado, especialmente em silagens produzidas com a adição 


\section{SILAGEM DE RESÍDUO ÚMIDO DE FÉCULA DE MANDIOCA ADICIONADA DE UREIA}

de alguma fonte de nitrogênio.

Resultado semelhante ao N-NH foi observado para o $\mathrm{N}$ total, porém, com significância apenas dos níveis de ureia $(\mathrm{p}<0,05)$, e aumento linear no $\mathrm{N}$ total das silagens com o aumento dos níveis de ureia adicionados (tabela II). Para cada $1 \mathrm{~g} / \mathrm{kg}$ de ureia adicionada ao resíduo úmido de fécula de mandioca com base na matéria natural, houve um aumento de $8,7 \mathrm{~g} / \mathrm{kg}$ de $\mathrm{NH}_{3}$ e de $0,913 \mathrm{~g} / \mathrm{kg}$ de $\mathrm{N}$ total, com base na matéria seca.

No estudo da composição bromatológica das silagens, constatou-se que os teores de matéria mineral, matéria orgânica, hemicelulose, lignina e celulose não foram alterados pelas fontes de variação estudadas $(p>0,05)$. No entanto, os teores de proteína bruta, FDN e FDA apresentaram significância para os níveis de ureia adicio$\operatorname{nados}(\mathrm{p}<0,05)$.

O teor de proteína bruta elevou-se linearmente com a adição dos níveis de ureia, apresentando um aumento de 5,72 g/ $\mathrm{kg}$ de $\mathrm{PB}$ na MS para cada $1 \mathrm{~g} / \mathrm{kg}$ de ureia adicionado na matéria natural do resíduo úmido de fécula de mandioca (tabela III). Aumentos nos teores de PB eram esperados devido à adição de ureia, e confirmam os benefícios do uso desse aditivo em condições críticas, como a desse estudo. Nas condições desse estudo, em que foi realizada a ensilagem de um material com baixo conteúdo de MS e com baixo conteúdo de $\mathrm{PB}$, a ureia proporcionou o aumento da PB com um baixo custo por unidade proteína obtida (Neuman et al., 2010).

Adição de ureia em níveis de $1 \%$ (Pedroso et al., 2007) ou de 0,5 a 1,5\% (Lima et al., 2002; Molina et al., 2002) da matéria natural são recomendados para aplicação na ensilagem da cana-de-açúcar, pois apresentam bom padrão de fermentação e melhor composição bromatológica, com teor mais elevado de MS e teores mais baixos de FDA e FDN, em comparação a silagens de cana exclusivamente. Porém, no caso do resíduo úmido de fécula de mandioca tais dosagens de ureia utilizadas se mostraram em excesso, possivelmente em virtude do baixo teor de MS desse subproduto.

Da mesma forma, o FDN e o FDA

Tabela III. Composição bromatológica $(\mathrm{g} / \mathrm{kg} \mathrm{MS})$ da silagem de resíduo úmido de fécula de mandioca com adição de níveis de ureia. (Chemical composition of wet residue of cassava starch silage with addition of urea levels).

\begin{tabular}{lcccccccccccc}
\hline & \multicolumn{4}{c}{ Níveis de ureia $^{1}$} & \multicolumn{2}{c}{ EPM1 } & EPM2 & \multicolumn{5}{c}{$\mathrm{p}$} \\
Variáveis & 0 & 5 & 10 & 15 & 20 & & & Nível (N) & Posição (P) & $N^{*} P$ & $L$ & FA \\
\hline MM & 24,3 & 24,2 & 24,1 & 24,2 & 24,0 & 0,08 & 0,05 & 0,999 & 0,212 & 0,939 & 0,795 & 1,000 \\
MO & 975,7 & 975,8 & 975,9 & 975,8 & 976,0 & 0,08 & 0,05 & 0,999 & 0,212 & 0,939 & 0,795 & 1,000 \\
PB $^{2}$ & 29,1 & 57,4 & 76,2 & 120,9 & 138,0 & 0,13 & 0,09 & 0,000 & 0,703 & 0,890 & 0,000 & 0,052 \\
FDN $^{3}$ & 411,0 & 402,1 & 416,9 & 411,3 & 417,5 & 0,34 & 0,27 & 0,037 & 0,823 & 0,965 & 0,049 & 0,062 \\
FDA $^{4}$ & 304,3 & 307,8 & 302,7 & 306,9 & 316,6 & 0,24 & 0,23 & 0,009 & 0,685 & 0,984 & 0,008 & 0,044 \\
HEM $^{106,6}$ & 94,3 & 114,2 & 104,4 & 100,9 & 0,39 & 0,23 & 0,054 & 0,507 & 0,916 & 0,919 & 0,170 \\
CEL & 248,4 & 246,7 & 244,6 & 259,9 & 261,3 & 0,80 & 0,54 & 0,494 & 0,823 & 0,782 & 0,198 & 0,637 \\
LIG & 67,2 & 65,5 & 65,7 & 63,1 & 64,2 & 0,47 & 0,31 & 0,081 & 0,522 & 0,880 & 0,886 & 0,054 \\
\hline
\end{tabular}

${ }^{1} \mathrm{~g} / \mathrm{kg}$ na matéria natural; $\mathrm{p}=$ significância testada ao nível de $5 \%$; $\mathrm{L}=$ regressão linear. $F A=$ falta de ajuste. ${ }^{2} Y=27,786+5,7162 X\left(R^{2}=0,979\right) ;{ }^{3} Y=407,302+0,4470 X\left(R^{2}=0,324\right) ;{ }^{4} Y=302,950+0,4734 X$ $\left(R^{2}=0,480\right) . M M=$ matéria mineral; $M O=$ matéria orgânica; $P B=$ proteína bruta; $F D N=$ fibra insolúvel em detergente neutro; FDA= fibra insolúvel em detergente ácido; $\mathrm{HEM}=$ hemicelulose; $L I G=$ lignina; $C E L=$ celulose. EPM1= erro padrão das médias da parcela; EPM2= erro padrão das médias da subparcela. 
elevaram-se linearmente, com um aumento de 0,45 e $0,47 \mathrm{~g} / \mathrm{kg}$, respectivamente, para cada $1 \mathrm{~g} / \mathrm{kg}$ de ureia adicionada (tabela III). $\mathrm{Na}$ ensilagem de materiais fibrosos, a ureia dentro do silo pode reduzir a FDN do material, pois em decorrência da ação da urease, é convertida a amônia, que, ao se ligar à água, forma o hidróxido de amônia, capaz de solubilizar os componentes da parede celular, principalmente a hemicelulose (Reis et $a l .$, 1990). No entanto, reduções na hemicelulose e na FDN não foram observadas no presente estudo, porque os conteúdos desses constituintes no material original era baixo, o que pode ter limitado os efeitos da ureia.

Para a determinação do valor nutritivo de alimentos para ruminantes é importante conhecer os teores de frações fibrosas dos alimentos. A digestibilidade da MS é negativamente correlacionada com o consumo, assim como com os teores de FDA e de FDN (Restle et al., 2000; Van Soest, 1994). Segundo Mühlbach (2003), o teor de FDN das forragens é o componente bromatológico responsável por regular o consumo de alimento. No resíduo úmido de fécula de mandioca in natura ou após a ensilagem com diferentes níveis de ureia, os valores obtidos para FDN estão abaixo dos recomendados por Mertens (1994), que cita valores na faixa de 55-60\% na base da matéria seca.

A hemicelulose é uma coleção heterogênea de polissacarídeos amorfos com grau de polimerização muito inferior a celulose (Van Soest, 1994). A ocorrência de hidrólise de carboidratos estruturais pela presença da ureia durante o processo de fermentação pode acarretar em alterações nos teores de hemicelulose (Mcdonald et al., 1991). Embora alguma celulose também possa ser hidrolisada, a hemicelulose é a principal fonte de carboidratos solúveis. Através de hidrólise química no caso da ureia, até $20 \%$ da hemicelulose pode ser hidrolisada em açúcares de 5 ou 6 carbonos, que foram utilizadas posteriormente por bactérias acéticas ou lácticas (Moser, 1995), fato que não ocorreu no presente estudo e que poderia ter contribuído para a redução do $\mathrm{pH}$.

$\mathrm{O}$ aumento nos teores de FDN e FDA, pode estar relacionado com o consumo dos carboidratos solúveis durante a fermentação (Mcdonald et al., 1991). Esse processo pode ter ocasionado perdas na matéria seca, fazendo com que o conteúdo total dessas frações fibrosas aumentasse. Também, segundo Vieira et al. (2004), a adição de ureia em silagens possui efeito negativo sobre o desenvolvimento e atuação de bactérias degradadoras da porção fibrosa da forragem (bactérias fibrolíticas), inibindo dessa forma a hidrólise da celulose.

A lignina é constituinte da parede celular, e influi negativamente sobre degradabilidade dos demais tecidos das plantas (Jung e Engels, 2002), e seu excesso pode indisponibilizar a proteína dietética, causando redução no consumo pelos animais (Rogerio et al., 2007). A ausência de alteração no conteúdo de lignina no presente estudo deve-se à ausência de hidrólise química no silo com liberação da hemicelulose, uma vez que aumentos na fração lignocelulósica de alimentos de origem vegetal conservados normalmente devem-se à redução nos conteúdos de hemicelulose.

A população de Clostridium da silagem, bem como os fungos e leveduras, e as bactérias ácido láticas foram alteradas pelos níveis de ureia adicionados $(\mathrm{p}<0,05)$ (tabela IV). Porém, apenas a população total de Clostridium apresentou diferença significativa para os pontos de amostragem, sendo superior na posição intermediária $(6,39$ $\log _{10}$ UFC/g) em relação à silagem da camada superficial do silo $\left(6,17 \log _{10} \mathrm{UFC} / \mathrm{g}\right)$. Essa diferença deve-se à drenagem de parte da água presente no RUFM para as camadas inferiores do silo. Embora essa diferença não tenha sido evidenciada pelos teores de matéria seca que foram semelhantes no momento da abertura dos silos (tabela II), no inicio do período de fermentação parte da água presente no RUFM permaneceu na 


\section{SILAGEM DE RESÍDUO ÚMIDO DE FÉCULA DE MANDIOCA ADICIONADA DE UREIA}

camada intermediária durante o processo de drenagem e lixiviação ao longo do perfil do silo. Esse processo permitiu um ambiente com maior umidade e mais favorável ao desenvolvimento de Clostridium na camada intermediária, no inicio do processo fermentativo, e está diferença foi mantida mesmo após a estabilização, drenagem total, do conteúdo de água excedente, no silo.

Em resposta aos níveis de ureia adicionados, para cada $\mathrm{g} / \mathrm{kg}$ de ureia adicionada houve uma redução de $0,292 \log _{10} \mathrm{UFC} / \mathrm{g}$ na população de Clostridium, ao passo que para os fungos e leveduras e bactérias ácido láticas, a redução foi de 0,354 e $0,378 \log _{10}$ $\mathrm{UFC/g}$, respectivamente (tabela IV).

As reduções observadas na população de microorganismos têm pouco impacto sobre a qualidade da silagem do ponto de vista biológico, pois a presença de ureia na massa ensilada normalmente ocasiona retardos na redução do $\mathrm{pH}$, devido à produção de hidróxido de amônio, favorecendo o crescimento de microorganismos indesejáveis que atuam em faixas de $\mathrm{pH}$ mais alto (Lopes e Evangelista, 2010).

No entanto, a formação do N-NH $\mathrm{NH}_{3}$ controla o desenvolvimento de alguns microorganismos (Siqueira et al., 2007). Segundo Freitas et al. (2002), a amônia $\left(\mathrm{NH}_{3}\right)$ formada a partir da ureia na presença de uréase possui ação antimicrobiana e inibindo o desenvolvimento de leveduras e fungos, justificando as reduções nas populações desses microrganismos apresentadas neste estudo.

Em relação às bactérias ácido láticas, grandes alterações na população não eram esperadas, pois a adição de ureia não estimula o crescimento desses microorganismos (Carvalho et al., 2011). Uma vez que estas possuem atividade eficaz da protease, não sendo eficientes na utilização da amônia (Hugenholtz e Kleerebezem, 1999). O que pode acarretar em maior competição com as bactérias capazes de utilizar nitrogênio não proteico (Carvalho et al., 2011), resultando em uma pequena redução das bactérias ácido láticas. Já para o Clostridium, os resultados comprovam que o aumento do $\mathrm{N}-\mathrm{NH}_{3}$ (tabela II) não tem relação direta com a população desses microrganismos, evidenciando que na ensilagem de produtos com baixo conteúdo de matéria seca com a adição de ureia, a presença de Clostridium não é o principal fator que contribui pra aumentos nos níveis de $\mathrm{N}-\mathrm{NH}_{3}$ das silagens.

\section{CONCLUSÃO}

A adição de ureia até o nível de $20 \mathrm{~g} / \mathrm{kg}$ na matéria natural para a ensilagem do

Tabela IV. Perfil microbiológico da silagem de resíduo úmido de fécula de mandioca com adição de níveis de ureia. (Microbiological profile of wet residue of cassava starch silage with addition of urea levels).

\begin{tabular}{|c|c|c|c|c|c|c|c|c|c|c|c|c|}
\hline \multirow[b]{2}{*}{ Variáveis ${ }^{1}$} & \multirow[b]{2}{*}{0} & \multicolumn{3}{|c|}{ Níveis de ureia ${ }^{2}$} & \multirow[b]{2}{*}{20} & \multirow[t]{2}{*}{ EPM1 } & \multirow{2}{*}{ EPM2 } & \multicolumn{5}{|c|}{$\mathrm{p}$} \\
\hline & & 5 & 10 & 15 & & & & Nível (N) & Posição (P) & $\mathrm{N}^{\star} \mathrm{P}$ & $\mathrm{L}$ & FA \\
\hline Clost $^{3}$ & 6,68 & 6,44 & 6,25 & 6,13 & 6,03 & 0,23 & 0,11 & 0,001 & 0,005 & 0,109 & 0,000 & 0,430 \\
\hline F-L ${ }^{4}$ & 6,70 & 6,33 & 6,13 & 6,12 & 5,91 & 0,26 & 0,04 & 0,000 & 0,330 & 0,793 & 0,000 & 0,415 \\
\hline $\mathrm{BAL}^{5}$ & 6,40 & 6,09 & 5,87 & 5,68 & 5,67 & 0,20 & 0,07 & 0,000 & 0,948 & 0,091 & 0,000 & 0,498 \\
\hline
\end{tabular}

${ }^{1} \mathrm{Log}$ UFC/g; $p=$ significância testada ao nível de $5 \%$; ${ }^{2} \mathrm{~g} / \mathrm{kg}$ na matéria natural; ${ }^{3} \mathrm{Y}=6,568-0,292 \mathrm{X}\left(\mathrm{R}^{2}=\right.$ $0,904) ;{ }^{4} Y=6,588-0,354 X\left(R^{2}=0,914\right) ;{ }^{5} Y=6,330-0,378 X\left(R^{2}=0,942\right)$. EPM1= erro padrão das médias da parcela; $E P M 2=$ erro padrão das médias da subparcela; $L=$ regressão linear; $F A=$ falta de ajuste; $U F C=$ unidade formadora de colônia. Clost= Clostridium; $\mathrm{F}-\mathrm{L}=$ fungos e leveduras; $\mathrm{BAL}=$ bactérias ácido láticas. 
resíduo úmido de fécula de mandioca com aproximadamente $180 \mathrm{~g} / \mathrm{kg}$ de MS aumenta o pH, $\mathrm{N}$ total, $\mathrm{N}_{-} \mathrm{NH}_{3}$, proteína bruta, FDN e FDA da silagem. Porém, reduz as populações de bactérias ácido láticas, fungos, leveduras e Clostridium sem alterar o conteúdo de matéria seca, a hemicelulose, celulose e

\section{BIBLIOGRAFIA}

Abrahao, J.J.S.; Prado, I.N.; Marques, J.A.; Perotto, D. e Lugão, S.M.B. 2006. Avaliação da substituição do milho pelo resíduo seco da extração da fécula de mandioca sobre o desempenho de novilhas mestiças em confinamento. Rev Bras Zootecn, 35: 512-518.

AOAC. 1990. Official methods of analysis. $15^{\mathrm{a}} \mathrm{ed}$. Association of Official Analytical Chemists. Arlington. Virginia. $1117 \mathrm{pp}$.

Benachio, S. 1965. Niveles de melaza en silo experimental de milho crillo (Sorghum vulgare). Agron Trop, 14: 291-297.

Bolsen, K.K.; Lin, C. and Brent, B.E. 1992. Effect of silage additives on the microbial succession and fermentation process of alfalfa and corn silage. J Dairy Sci, 75: 3066-3083.

Caldas Neto, S.F.; Zeoula, L.M.; Branco, A.F.; Prado, I.N.; Dalponte, A.O.; Kassies, M. e Fregadolli, F.L. 2000. Mandioca e resíduos das farinheiras na alimentação de ruminantes: digestibilidades total e parcial. Rev Bras Zootecn, 26: 2099-2108.

Carvalho, D.D.; Andrade, J.B. e Biondi, P. 1992. Estádio de maturação na produção e qualidade da silagem de sorgo. I Produção de matéria seca e proteína bruta. Bol Ind Anim, 49: 91-99.

Carvalho, I.P.; Detmann, E.; Mantovani, H.C.; Paulino, M.F.; Valadares, Filho, S.C.; Costa, V.A.C. and Gomes, D.I. 2011. Growth and antimicrobial activity of lactic acid bacteria from rumen fluid according to energy or nitrogen source. Rev Bras Zootecn, 40: 1260-1265.

Freitas, D.; Coan, R.M.; Reis, R.A. Pereira, J.R.A. e Panizzi, R.C. 2002. Avaliação de fontes de amônia para conservação do feno de alfafa (Medicago sativa L.) armazenado com alta umidade. Rev Bras Zootecn, 31: 866-874.

Gomide, J.A.; Assis, F.N. e Nascimento, D.J. 1974. Efeito da adição de ureia e do tempo de lignina. Apesar de a ureia contribuir com o aspecto nutricional da silagem de resíduo úmido de fécula de mandioca, elevando os teores de proteína bruta, são necessários novos estudos mais detalhados para a recomendação da utilização desse volumoso na alimentação animal.

fermentação sobre as características da silagem de sorgo (Sorghum vulgare). Rev Ceres, 21: 358-365.

Gonçalves, J.A.G.; Zambom, M.A.; Fernandes, T.; Mesquita, E.E.; Schimidt, E.; Javorski, C.R. e Castagnara. D.D. 2014. Composição químicobromatológica e perfil de fermentação da silagem de resíduo úmido de fécula de mandioca. Bios Journ, 30: 502-511.

Jobim, C.C. e Golçalves, G.D. 2003. Microbiologia de forragem conservada. In: R. Andrade Reis et al. (Eds.). Volumosos na produção de ruminantes: Valor alimentício de forragens. Funep. Jaboticabal. 264 pp.

Jobim, C.C.; Nussio, L.G.; Reis, R.A. e Schimidt, P. 2007. Avanços metodológicos na avaliação da qualidade da forragem conservada. Rev Bras Zootecn, 36: 101-119.

Jung, H.G. and Engels, F.M. 2002. Alfalfa stem tissues: cell, wall deposition, composition and degradability. Crop Sci, 24: 524-534.

Hugenholtz, J. and Kleerebezem, M. 1999. Metabolic engineering of lactic acid bacteria: overview of the approaches and results of pathway rerouting involved in food fermentations. Food Biotechnol, 10: 492-497.

Kung Jr., L.; Stokes, M.R. and Lin, C.J. 2003. Silage additives. In: Buxton, D.R.; Muck, R.E.; Harrison, J.H. (Eds.) Silage science and technology. American Society of Agronomy, Crop Science Society of America, Soil Science Society of America. Madison. pp: 251-304.

Lima, J.A.; Evangelista, A.R. e Abreu, J.G. 2002. Silagem de cana-de-açúcar (Saccharum officinarum $\mathrm{L}$.) enriquecida com ureia ou farelo de soja. Reunião Anual da Sociedade Brasileira de Zootecnia, 39. Recife. Anais... Sociedade Brasileira de Zootecnia. Recife.

Lopes, J. e Evangelista, A.R. 2010. Característi-

Archivos de zootecnia vol. 63, num. 244, p. 686. 


\section{SILAGEM DE RESÍDUO ÚMIDO DE FÉCULA DE MANDIOCA ADICIONADA DE UREIA}

cas bromatológicas, fermentativas e população de leveduras de silagens de cana-de-açúcar acrescidas de ureia e aditivos absorventes de umidade. Rev Bras Zootecn, 39: 984-991.

Marques, J.A. e Caldas Neto, S.F. 2002. Mandioca na alimentação animal: Parte aérea e raiz. CIES. Campo Mourão. PR. 28 pp.

McDonald, P.; Henderson, A.R. and Heron, S.J.E. 1991. The biochemistry of silage. $2^{\mathrm{a}} \mathrm{ed}$. Chalcombe Publications. Marlow. 340 pp.

Mertens, D.R. 1994. Regulation of forage intake. In: Fahey Jr, G.R. Forage quality, evaluation and utilization. American Society of Agronomy. Madison, WI. pp: 450-493.

Meeske, R.; Ashbell, G.; Weinberg, Z.G. and Kipnis, T. 1993. Ensiling forage sorghum at two stages of maturity with the addition of latic acid bacterial inoculants. Animal Feed Sci Tech, 43: 165-175.

Molina, L.R.; Ferreira, D.A.; Gonçalves, L.C.; Castro Neto, A.G. e Rodrigues, N.M. 2002. Padrão de fermentação da silagem de cana-de-açúcar (Saccharum officinarum L.) submetida a diferentes tratamentos. Reunião Anual da Sociedade Brasileira de Zootecnia, 39. Recife. Anais... SBZ. Recife.

Moser, L.E. 1995. Post-harvest physiological changes in forage plants. In: Moore, K.J., Kral, D.M. and Viney, M.K. (Eds.). Post-harvest physiology and preservation of forages. American Society of Agronomy Inc. Madison, Wisconsin. pp. 1-19.

Mühlbach, P.R.F. 2003. Produção de leite com vacas de alta produtividade. Reunião Anual da Sociedade Brasileira de Zootecnia, 40. Santa Maria. Anais... Sociedade Brasileira de Zootecnia. São Paulo.

Neumann, M.; Oliboni, R.; Oliveira, M.R.; Faria, M.V.; Ueno, R.K.; Reinerh, L. e Durman, T. 2010. Aditivos químicos utilizados em silagens. Pesqui Aplic Agrotecnol, 3: 187-195.

Paiva, J.A.J. 1976. Qualidade da silagem da região metalúrgica de Minas Gerais. Dissertação. (Mestrado em Ciência Animal). Universidade Federal de Minas Gerais. Belo Horizonte. 86 pp.

Pedroso, A.F.; Nussio, L.G.; Loures, D.R.S.; Paziani, S.F.; Igarasi, M.S.; Coelho, R.M.; Horii, J. e Rodrigues, A.A. 2007. Efeito do tratamento com aditivos químicos e inoculantes bacterianos nas perdas e na qualidade de silagens de canade-açúcar. Rev Bras Zootecn, 36: 558-564.
Pimentel-Gomes, F.e Garcia, C. H. 2002. Estatística aplicada a experimentos agronômicos e florestais: exposição com exemplos e orientações para uso de aplicativos. $11^{\underline{a}}$ ed. FEALQ. Piracicaba, 309 pp.

Pimentel-Gomes, F.P. 2009. Curso de estatística experimental. 15 ${ }^{\mathrm{a}}$ ed. FEALQ. Piracicaba. 451 pp.

Ramalho, R.P.; Ferreira, M.A.; Véras, A.S.C.; Lima, L.E. e Rocha, V.R.R.A. 2006. Substituição do milho pela raspa de mandioca em dietas para vacas primíparas em lactação. Rev Bras Zootecn, 35: 1221-1227.

Reis, R.A.; Garcia, R.; Queiroz, A.C.; Silva, D.J. e Ferreira, J.Q. 1990. Efeitos da aplicação de amônia anidra sobre a digestibilidade do feno de capim-brachiaria (Bracharia decumbens Stapf). Rev Bras Zootecn, 19: 201-208.

Restle, J.; Alves Filho, D.C.; Brondani, I.L. e Flores, J.L.C. 2000. Palha de soja (Glicine max) como substituto parcial da silagem de sorgo forrageiro (Sorghum bicolor L. Moench) na alimentação de terneiros de corte confinados. Ciênc Rural, 30: 319-324.

Ribeiro, C.G.M.; Gonçalves, L.C.; Rodrigues, J.A.S.; Rodriguez, N.M.; Borges, I.; Borges, A.L.C.C.; Saliba, E.O.S.; Castro, G.H.F. e Ribeiro Junior, G.O. 2007. Padrão de fermentação da silagem de cinco genótipos de sorgo. Arq Bras Med Vet Zoo, 59: 1531-1537.

Rogerio, M.C.P.; Borges, I.; Neiva, J.N.M.; Rodriguez, N.M.; Pimentel, J.C.M.; Martins, G.A.; Ribeiro, T.P.; Costa, J.B.; Santos, S.F. e Carvalho, F.C. 2007. Valor nutritivo do resíduo da indústria processadora de abacaxi (Ananas comosus L.) em dietas para ovinos. Consumo, digestibilidade aparente e balanços energético e nitrogenado. Arq Bras Med Vet Zoo, 59: 773-781.

Rotz, C.A. and Muck, R.E. 1994. Changes in forage quality during harvest and storage. In: Fahey Jr., G.C. (Ed.). Forage quality, evaluation, and utilization. American Society of Agronomy. Madison. pp. 828-868.

Silva, N.; Junqueira, V.C.A. e Silveira, N.F.A. 1997. Manual de métodos de análise de alimentos. Livraria Varela.São Paulo. 295 pp.

Silva, D. J. e Queiroz, A.C. 2006. Análise de alimentos: métodos químicos e biológicos. Ed. UFV. Viçosa, MG. 235 pp.

Siqueira, G.R.; Reis, R.A.; Schocken-Iturrino, R.P.; 
Bernardes, T.F.; Pires, A.J.V.; Roth, M.T.P. e Roth, A.P.T. 2007. Associação entre aditivos químicos e bacterianos na ensilagem de canade-açúcar. Rev Bras Zootecn, 36: 789-798.

Souza, L.C.;Zambom, M.A.; Pozza, M.S.S.; Neres, M.A.; Radis, A.C.; Borsatti, L.; Castagnara, D.D. and Gundt, S. 2012. Development of microorganisms during storage of wet brewery waste under aerobic and anaerobic conditions. Rev Bras Zootecn, 41: 188-193.

Van Soest, P.J. 1994. Nutritional ecology of the ruminant. Constock Publishing Associates. Ithaca. $476 \mathrm{pp}$.

Van Soest, P.J. Robertson, J.B. and Lewis, B.A. 1991. Methods for dietary fiber, neutral detergent fiber and non starch polysaccharides in relation to animal nutrition. J Dairy Sci, 74: 3583-3597. Vieira, F.A.P.; Borges, I.; Stehling, C.A.V.; Gonçalves,L.C.; Coelho, S.G.; Ferreira, M.I.C.e Rodrigues, J.A.S. 2004. Qualidade de silagens de sorgo com aditivos. Arq Bras Med Vet Zoo, 56: 764-772.

Archivos de zootecnia vol. 63, num. 244, p. 688. 